\title{
APPLYING DESIGN OF EXPERIMENTS TO DEVELOP A FUEL INDEPENDENT HEAT TRANSFER MODEL FOR SPARK IGNITION ENGINES
}

\author{
${ }^{1}$ Demuynck, Joachim $;{ }^{2}$ Chana, Kam ; ${ }^{1}$ De Paepe, Michel; ${ }^{1}$ Sileghem, Louis; ${ }^{1}$ Vancoillie, \\ Jeroen; ${ }^{1}$ Verhelst, Sebastian; \\ ${ }^{1}$ Ghent University, Belgium; ${ }^{2}$ University of Oxford, United Kingdom
}

KEYWORDS - heat transfer, internal combustion engine, design of experiments, model, alternative fuel

\begin{abstract}
Models for the convective heat transfer from the combustion gases to the walls inside a spark ignition engine are an important keystone in the simulation tools which are being developed to aid engine optimization. The existing models are, however, inaccurate for an alternative fuel like hydrogen. This could be caused by an inaccurate prediction of the effect of the gas properties. These have never been varied in a wide range before, because air and 'classical' fossil fuels have similar values, but they are significantly different in the case of hydrogen. We have investigated the effect of the gas properties on the heat flux in a spark ignition engine by injecting different inert gases under motored operation and by using different alternative fuels under fired operation. Design of Experiments has been applied to vary the engine factors in a systematic way over the entire parameter space and to determine the minimum required amount of combinations. This paper presents the validation of a heat transfer model based on the Reynolds analogy for the entire experimental dataset. The paper demonstrates that the heat flux can be accurately predicted during the compression stroke with a constant characteristic length and velocity, if appropriate polynomials for the gas properties are used. Furthermore, it shows that a two-zone combustion model needs to be used as a first step to capture the effect of the flame propagation. However, alternative characteristic lengths and velocities will need to be investigated to capture the intensified convective heat transfer caused by the propagating flame front and to accurately predict the heat flux during the expansion stroke.
\end{abstract}

\section{INTRODUCTION}

A lot of research efforts focus on further improving the efficiency, emissions and power output of internal combustion engines (ICE) to propel ever heavier vehicles with lower fuel consumption and emissions. To enhance this development, computer tools are being developed to simulate the engine cycle. An important part in these models is the prediction of the heat transfer inside the engine, since it has an effect on all the improvement targets given above. In particular, the convective and radiant heat transfer from the combustion gases to the inner cylinder walls is needed at every calculation step to solve the conservation equations of mass and energy. Therefore, in-cylinder heat transfer has been the subject of many research programs since the 1950s [1, 2]. In spark ignition engines, only convection is considered since radiation is negligible [1]. Although the heat transfer process inside an engine is transient, it is assumed to be quasi-steady. As a consequence, the convective component of the heat flux (q) can be described by a convection coefficient (h), defined in equation 1 .

$$
h=\frac{q}{\left(T_{g}-T_{w}\right)}
$$


Where $T_{\mathrm{w}}$ is the wall temperature and $\mathrm{T}_{\mathrm{g}}$ the bulk gas temperature. The underlying assumption of most of the models in literature, e.g. refs. [3-5], is the Reynolds analogy [6], which describes the analogous behaviour of heat and momentum transfer. The analogy results in a relation between the Nusselt $(=h . L / k)$, Reynolds $(=V . L / v)$ and Prandtl $(=\alpha / v)$ number, given in equation 2 . The models differ in the choice of the parameters $(a, b$ and $c)$ and the characteristic length (L) and velocity (V).

$$
N u=a \cdot R e^{b} \cdot P r^{c}
$$

Although there has been a lot of research on the heat transfer in combustion engines, the mechanisms are still not well characterized, especially not for new combustion types (e.g. HCCI) and alternative fuels (e.g. hydrogen [7, 8]). The most obvious possible reason for the models being inaccurate for an alternative fuel like hydrogen, is that the effect of the gas properties is not well captured. These gas properties have never been significantly varied before, since only air and fossil fuels with comparable properties have been used. Next, the effect of the Prandtl number has often been neglected. Furthermore, assumptions on the temperature dependency of the gas properties were made instead of using proper polynomials. The resulting error for fossil fuels could be small, but the thermal conductivity and heat capacity of hydrogen, on the other hand, differ significantly compared to air.

Solving the unsteady, one-dimensional energy equation for the boundary layer has been proposed as an alternative [9] for the quasi-steady assumption presented above. However, additional assumptions have to be made and it has not yet been demonstrated that this approach results in more accurate predictions. Therefore, this paper will investigate the applicability of the Reynolds analogy to model the convective heat transfer inside a spark ignition engine. It will mainly focus on the effect of the thermal conductivity $(\mathrm{k})$, viscosity $(v)$, heat capacity $\left(c_{p}\right)$ and density on the heat flux in an SI-ICE in an attempt to develop a model that is capable of simulating the difference in the heat flux between different fuels. The gas properties are varied in a wide range by injecting different inert gases (helium, argon, carbon dioxide) under motored operation an by using different alternative fuels (hydrogen, methane, methanol) under fired operation. In addition to the gas properties, the effect of the following engine factors is investigated: the throttle position (TP), the compression ratio (CR), the ignition timing (IGN) and the air-to-fuel equivalence ratio $(\lambda)$. The experiments are designed and analysed with methods of Design of Experiments to investigate the variable engine factors in a consistent way over the entire parameter space.

\section{EXPERIMENTAL METHOD}

\section{$\underline{\text { Equipment }}$}

The research is conducted on a CFR (Cooperative Fuel Research) engine, which is a fourstroke single-cylinder spark ignition engine. It has a variable compression ratio, but can only be operated at a constant speed of $600 \mathrm{rpm}$. The engine is equipped with a port fuel injection system. Two types of injectors are available, one for gaseous fuels and one for liquid fuels. The injection and ignition is controlled by a MoTeC M4Pro electronic control unit. Figure 1 shows the possible mounting positions for sensors in the engine. Table 1 gives an overview of the relevant engine properties. The CFR engine has recently been revised, resulting in a larger bore diameter and different valve timings compared to older publications. 
Table 1: CFR-Engine properties

\begin{tabular}{|c|c|}
\hline Bore & $83.06 \mathrm{~mm}$ \\
\hline Stroke & $114.2 \mathrm{~mm}$ \\
\hline Connecting rod length & $254 \mathrm{~mm}$ \\
\hline Swept Volume & $618.8 \mathrm{~cm}^{3}$ \\
\hline IVO & $10^{\circ} \mathrm{CA}$ ATDC \\
\hline IVC & $29^{\circ} \mathrm{CA} \mathrm{ABDC}$ \\
\hline EVO & $39^{\circ} \mathrm{CA}$ BBDC \\
\hline EVC & $12^{\circ} \mathrm{CA}$ ATDC \\
\hline
\end{tabular}
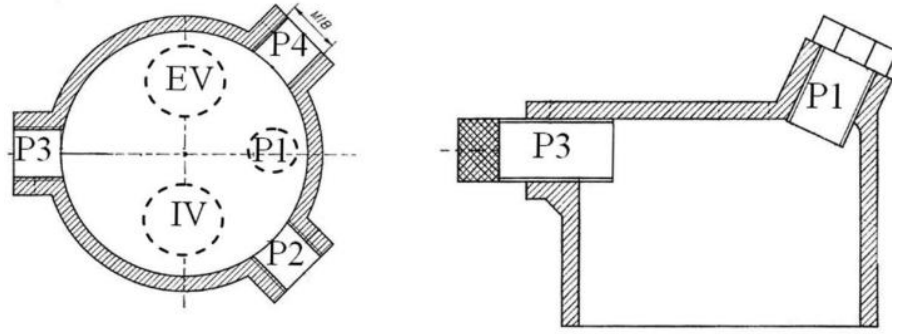

Figure 1: Cross section of the CFR engine, $\mathrm{P} 1$ : spark plug position, $\mathrm{P} 2-\mathrm{P} 4$ : sensor positions, IV: intake valve, EV: exhaust valve

The heat flux and wall temperature are measured at positions P2, P3 and P4 with a Vatell HFM-7 sensor. The measurement positions are at the same height in the cylinder wall and are equally distributed around the circumference of the cylinder. The spark plug was mounted in position P1. The compression ratio has to be kept below 10, because the moving piston would otherwise damage the heat flux sensor. More detailed information on the test bench can be found in previous publications $[7,10]$.

\section{$\underline{\text { Experimental design }}$}

Both the experiments under motored and fired operation were designed according to DoE methods (Design of Experiments) described in ref. [11]. The purpose of the DoE is to vary several factors in a systematic way and to define the minimum required number of combinations to investigate the heat flux in the entire parameter space, because it was not possible to run all the combinations. The statistical analysis of each experiment results in an experimental surface of the heat flux over the entire parameter space. This experimental surface will be compared with the surface obtained by the model prediction to test the model's capability of predicting the effect of engine factors in addition to variations within a certain engine cycle.

A detailed description of the experimental design of the measurements under motored operation can be found in ref. [10]. In summary, three inert gases were injected in the intake manifold with the injector which is normally used to inject a gaseous fuel: helium, argon and carbon dioxide. In addition to the type and quantity of the gas, the compression ratio and throttle position were varied. The throttle position can be varied between 0 and $87^{\circ}$, but it only affects the ingoing flow rate when varied between 63 and $87^{\circ}$, because of the low engine speed. These two values will be labelled as wide open throttle (WOT) and fully closed throttle (FCT). The heat flux was only measured at P2, as we observed from previous measurements that there is no significant spatial variation in the heat flux under motored operation.

For the measurements under fired operation, a Response Surface Method (RSM), more specifically a Central Composite Design (CCD), was used. Consequently, each factor was tested at 5 levels (coded as -2, -1, 0, 1 and 2). Since the fuel and measurement position are categorical factors, they were not included in the DoE design and the RSM was repeated for all the levels of these factors (three times for the different measurement positions and three times for the different fuels). The levels of IGN and $\lambda$ are fuel dependent to cover the optimal and widest possible range for each fuel. A combined wide range of IGN and $\lambda$ was not possible for hydrogen, due to the occurrence of abnormal combustion at the extreme combinations (e.g. an early ignition for rich mixtures). Consequently, $\lambda$ has been varied at the 
lean side for hydrogen to cover the widest possible range for IGN. An overview of the extreme levels of the continuous factors is given in Table 2.

\begin{tabular}{|c|c|c|c|}
\hline factor & fuel & level & level code \\
\hline \multirow{2}{*}{$\mathrm{TP}$} & \multirow{2}{*}{ all } & fully closed throttle (FCT) & -2 \\
\hline & & wide open throttle (WOT) & 2 \\
\hline \multirow{2}{*}{$\mathrm{CR}$} & \multirow{2}{*}{ all } & 8 & -2 \\
\hline & & 10 & 2 \\
\hline \multirow{6}{*}{ IGN } & \multirow{2}{*}{$\mathrm{CH}_{4}$} & $38^{\circ} \mathrm{ca} \mathrm{BTDC}$ & -2 \\
\hline & & $10^{\circ} \mathrm{ca} \mathrm{BTDC}$ & 2 \\
\hline & \multirow{2}{*}{$\mathrm{H}_{2}$} & $5^{\circ} \mathrm{ca} \mathrm{BTDC}$ & -2 \\
\hline & & $-15^{\circ} \mathrm{ca} \mathrm{BTDC}$ & 2 \\
\hline & \multirow{2}{*}{$\mathrm{CH}_{3} \mathrm{OH}$} & $25^{\circ} \mathrm{ca} \mathrm{BTDC}$ & -2 \\
\hline & & $5^{\circ} \mathrm{ca} \mathrm{BTDC}$ & 2 \\
\hline \multirow{6}{*}{$\lambda$} & \multirow{2}{*}{$\mathrm{CH}_{4}$} & 1.2 & -2 \\
\hline & & 0.8 & 2 \\
\hline & \multirow{2}{*}{$\mathrm{H}_{2}$} & 2.2 & -2 \\
\hline & & 1.4 & 2 \\
\hline & \multirow{2}{*}{$\mathrm{CH}_{3} \mathrm{OH}$} & 1.3 & -2 \\
\hline & & 0.7 & 2 \\
\hline
\end{tabular}

It was not possible to run the full factorial CCD (testing all the possible combinations) for all the measurement positions for a certain fuel, so a fractional factorial design was selected. No information was available in literature on which interactions could be neglected.

Consequently, the full factorial experiment was run in one measurement position (P2) on methane to provide this information. The ANOVA (analysis of variance) results of that experiment showed that only interactions of IGN with the other factors were significant. To have a clean estimation of all the main effects and the interactions of IGN with CR, TP and $\lambda$, a fractional factorial design of half of all the possible cubical points (combinations of the factors at the levels -1 and 1) could be run. This fractional factorial design enabled the completion of an entire measurement set for a certain fuel on one day.

\section{Data reduction}

The Nusselt, Reynolds and Prandtl number were calculated for a total of 18 points between 290 and $420^{\circ} \mathrm{ca}$ (most important part of the cycle) for each of the cases to build the database for the model validation. Several properties are needed to determine those dimensionless numbers, which are described here. First, the bulk gas temperature needs to be calculated, in addition to the measurement of the heat flux and wall temperature, to determine a convection coefficient out of equation 1 . That bulk gas temperature is derived from the measured incylinder pressure with a Three-Pressure-Analysis (TPA) in GT-Power [12]. For motored measurements, a uniform temperature is assumed throughout the combustion chamber. For fired operation, a two-zone gas temperature approach is used, where the in-cylinder volume is divided in an unburned and a burned zone to capture the effect of the propagating flame front. Furthermore, the gas properties need to be calculated for each zone. Polynomials for those gas properties of the pure components as a function of temperature are taken from the DIPPR database [13]. The properties of the unburned and burned mixtures during the engine cycle are calculated from the ones of the pure components with the proper mixing laws described in ref. [14]. At a certain measurement position, the gas properties and gas temperature are switched from unburned to burned at the instant the propagating flame front arrives at the measurement position. In this paper, this is determined by the instant the derivative of the heat flux trace exceeds a certain threshold value. 


\section{RESULTS AND DISCUSSION}

The entire database was divided in six different flow regimes to be able to study the effect of the engine factors and gases in a systematic way without and with the presence of a propagating flame front:

1. compression stroke before ignition

2. compression stroke after ignition, in contact with the unburned zone

3. compression stroke after ignition, in contact with the burned zone

4. expansion stroke, in contact with the unburned zone

5. expansion stroke, in contact with the burned zone

6. expansion stroke after the end of combustion

The measurements under motored operation belong to part 1 or 6 . A regression analysis will be used to determine the parameters $a, b$ and $c$ in equation 2 . The Prandtl number only differs significantly for a limited part of the dataset. Consequently, the ability of the Reynolds analogy to predict the heat flux for the different parts can be visualised by plotting the Nusselt number against the Reynolds number on a logarithmic scale. This is shown in Figure 2 for the reference case of a constant characteristic length (engine bore) and velocity (mean piston speed), as chosen by Annand [3]. The different gases and fuels are plotted in a different colour and different markers are used for the measurement positions. The graph shows that there is a strong linear relation between the two dimensionless numbers in the first and second part, indicating that the Reynolds analogy could be appropriate to model the heat flux within a spark ignition engine. However, the relation for regimes 3-5 is not linear at all in the reference case. Part 6 again shows a linear trend, but each case has a different offset.

First, it will be demonstrated that the Reynolds analogy accurately predicts the differences caused by the gas properties and engine effects for part 1 if a constant $\mathrm{L}$ and $\mathrm{V}$ are used (will be referred to as model 1). The usage of proper polynomials and mixing laws for the gas properties is a necessity. This is, however, not the case for some models in literature as mentioned above, e.g. ref. [5], so these models even fail to predict the differences for flow regime 1. Furthermore, the regression analysis of the data showed that the effect of the Prandtl number differed depending on its level. Therefore, the model parameters have been determined for two groups according to the level of the Prandtl number, as shown in Table 3. The exponent of Re is very similar between the two groups, but the exponent of Pr of the second group has an unexpected value. The data actually indicated that there was no significant effect of the Prandtl number between 0.675 and 0.74 , so the regression analysis resulted in an artificial exponent which needs further investigation. The Pr number did show a clear effect for helium and hydrogen, causing the offset in the data in Figure 2 for these gases.

\begin{tabular}{c|c|c}
\multicolumn{3}{c}{ Table 3: model parameters for part 1} \\
parameter & $0.475<\operatorname{Pr}<0.675$ & $0.675<\operatorname{Pr}<0.74$ \\
\hline $\mathrm{a}$ & 2.67 & 1.71 \\
$\mathrm{~b}$ & 0.573 & 0.549 \\
$\mathrm{c}$ & 0.872 & -0.614
\end{tabular}




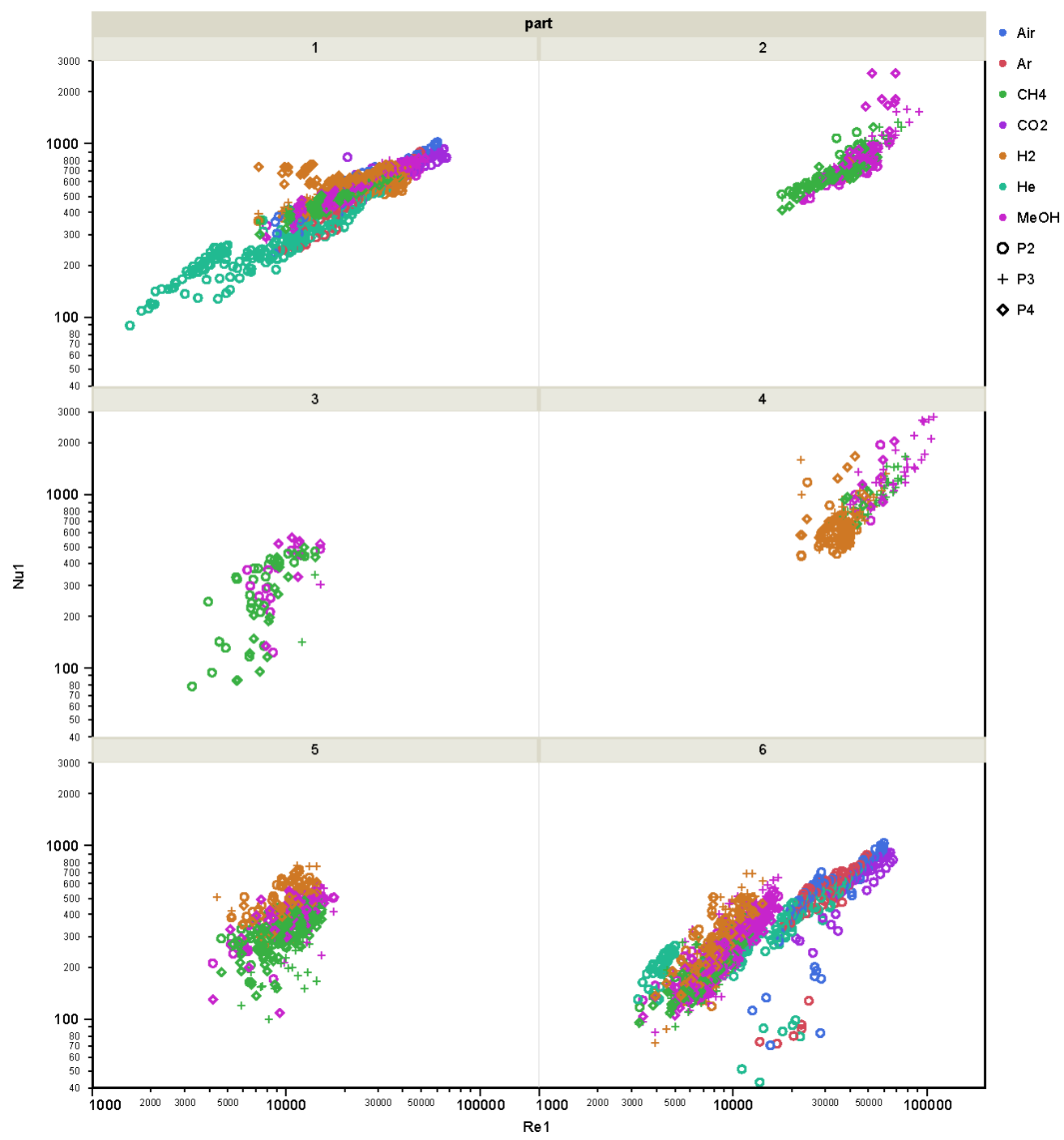

Figure 2: The relation between the Nusselt and Reynolds number on a logarithmic scale for the six flow regimes

The following figures will compare the measured peak heat fluxes with those predicted by model 1 for the motored measurements (belonging to part 1). The effect for each gas is plotted in a different colour. The measurements are plotted with a filled marker (connected with trend lines) and the model predictions with an unfilled marker. Error bars are added for the experimental uncertainty on the measured heat flux to indicate the accuracy of the model predictions. For the measurements with the inert gases, Figure 3 - Figure 5 show that only the

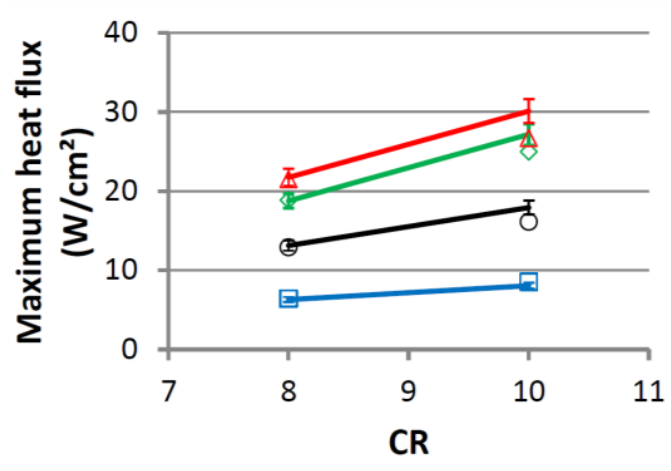

Figure 3: The model does not accurately predict the effect of CR for helium, argon and air

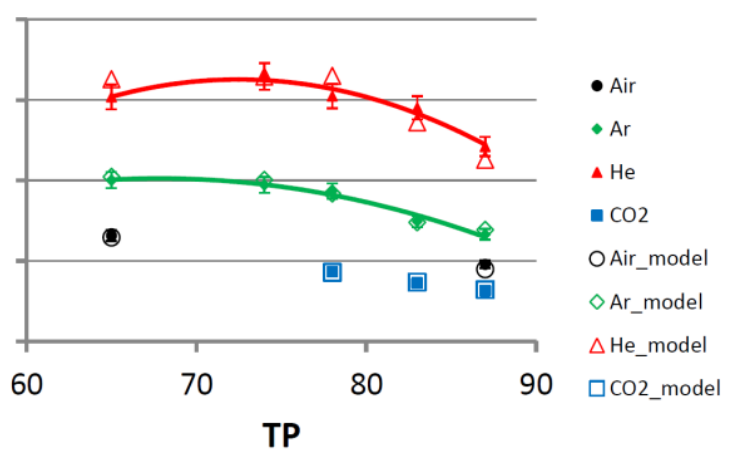

Figure 4: The model accurately predicts the effect of the throttle position $(65=$ WOT, $87=\mathrm{FCT})$ 


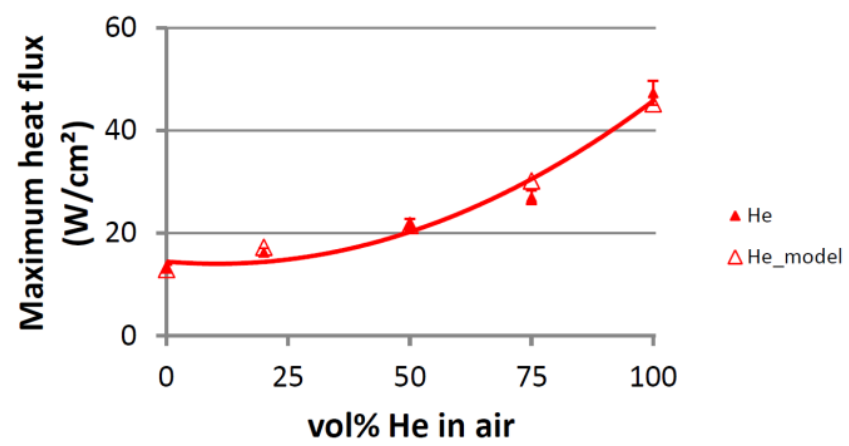

Figure 5: The model is capable of predicting the increasing heat flux when the amount of helium is augmented

effect of the compression ratio (Figure 3 ) is not accurately predicted by model 1 (for air, argon and helium). The model does accurately predict the effect of the throttle position (Figure 4) and the effect of an increasing addition of helium in the ingoing air flow (Figure 5). However, it is noteworthy that the plotted error bars only show the experimental uncertainty in the measured heat flux $( \pm 5 \%)$. The resulting error in the derived convection coefficient which is being modelled is significantly higher $( \pm 11 \%)$. Consequently, if this is taken into account, the model accurately predicts all the effects within the experimental uncertainty. The same results are obtained for part 1 of the measurements under fired operation. Figure 6 compares the effect of TP and CR predicted by the model with that obtained out of the measurements at $320^{\circ} \mathrm{ca}$, being the last instant in the cycle belonging to part 1 for all the cases (earliest ignition for $\mathrm{CH} 4$ is $38^{\circ} \mathrm{ca} \mathrm{BTDC}$ ). The simulation results are slightly outside the experimental uncertainty on the measured heat flux, but this is negligible taking into account the remark about the actual uncertainty on the convection coefficient given above.

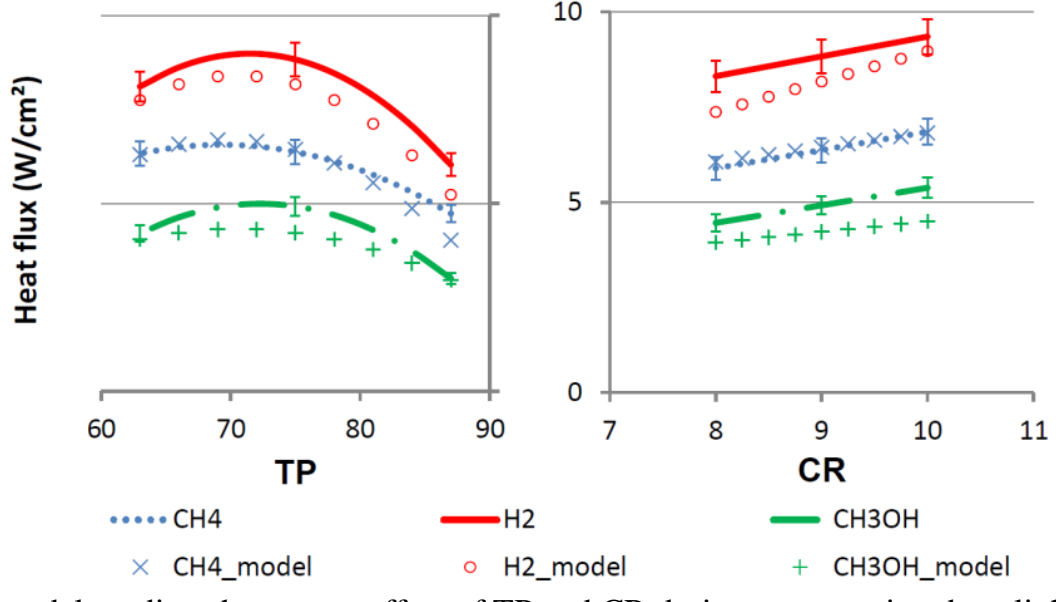

Figure 6: The model predicts the correct effect of TP and CR during compression, but slightly outside the measurement uncertainty

Figure 7 demonstrates that model 1 also accurately predicts the instantaneous heat flux within the cycle during the compression stroke for the motored measurements. However, the model fails to predict the heat flux during the expansion stroke (flow regime 6). The discontinuity between compression and expansion is caused by a different model fit for part 6 which is not presented here. Alternative lengths (2) and velocities (1) proposed in the literature have been explored and some improved the model fit. The first alternative length was suggested by Hohenberg et al. [12], being the diameter of a sphere with the same volume as the in-cylinder volume. The second one was the height above the piston, which was suggested by Chang et al. [15]. None of these lengths improved the data fit. The alternative velocity was suggested by 
Morel et al. [4] and included the effect of the turbulent kinetic energy. This model is referred to as model 2 and its predictions are added in Figure 7. The results show that the fit is improved compared to model 1 . However, the results are still not accurately enough.

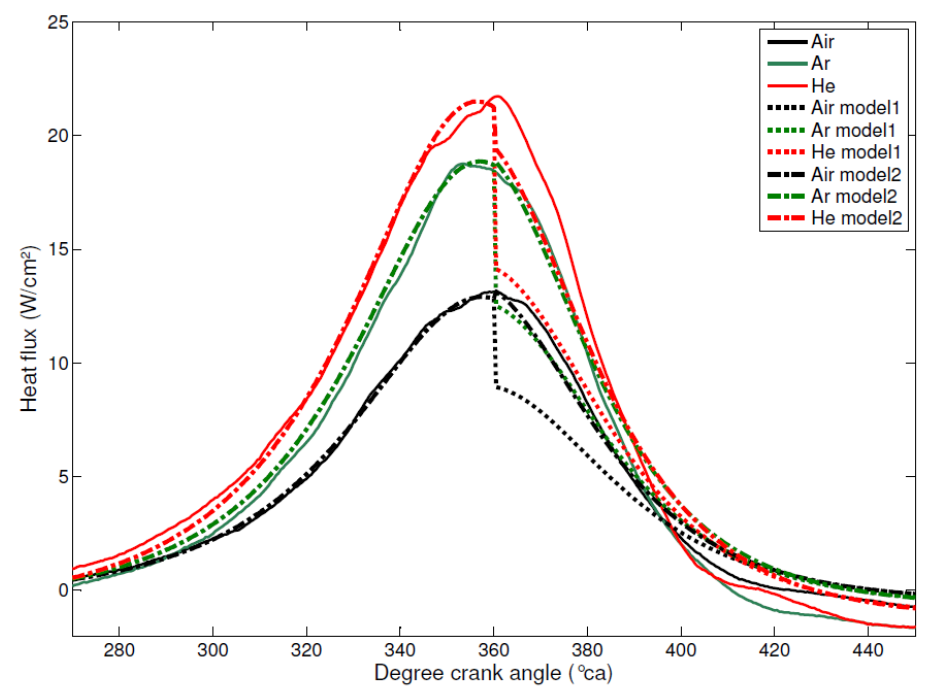

Figure 7: Measured heat flux vs. model predictions under motored operation at $\mathrm{P} 2(\mathrm{CR}=8$, WOT)

The most important heat loss occurs during combustion and model 1 also fails in the simulation of the peak heat flux under fired operation for hydrogen and methanol. Figure 8 shows that satisfactory predictions are obtained for methane and that the effect of the engine factors (CR and TP are not shown here) is well predicted, except the effect of $\lambda$ for hydrogen. However, model 1 predicts an average heat flux level for hydrogen and methanol which is too low. The alternative lengths and velocities presented above did not result in more accurate results and Figure 9 indicates that this is caused because of the effect of the flame propagation which is not yet fully captured. Using a two-zone combustion model can only partially explain the initial increase in the heat flux at the instant the propagating flame front arrives at the measurement position. The second peak in the measured heat flux trace is being captured by the model because it is caused by the peak in the burned gas temperature. The first peak must occur because the propagating flame front results in an intensified convective heat transfer or a momentarily larger gas temperature. The alternative lengths and velocities did

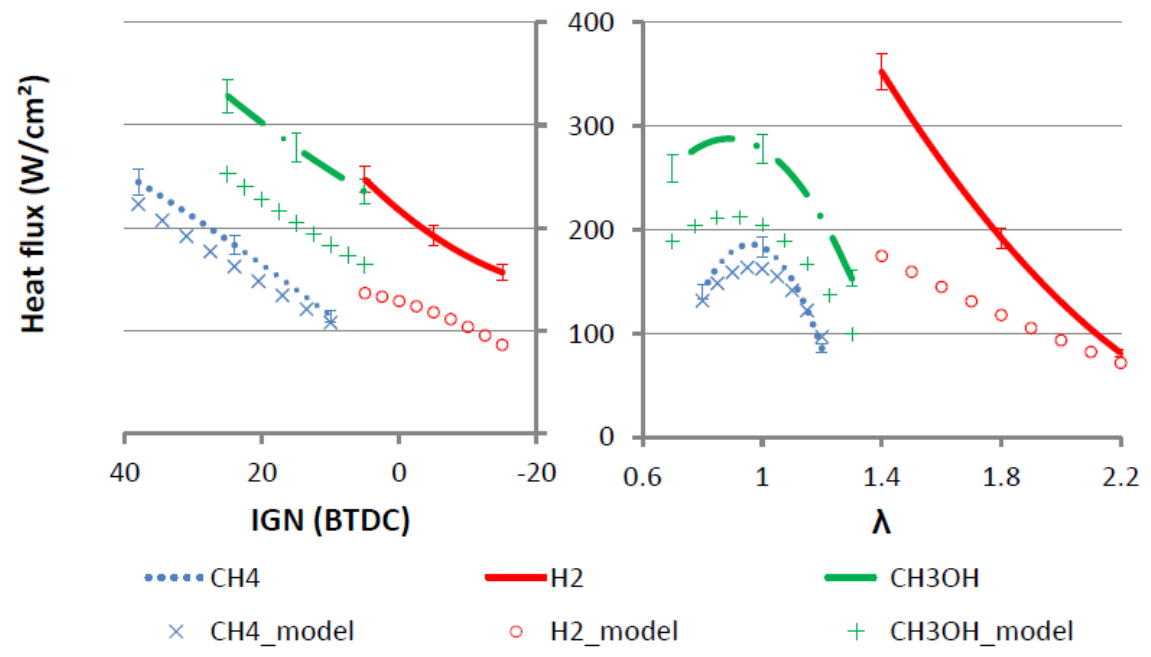

Figure 8: The model fails to predict the correct peak heat flux under fired operation for hydrogen and methanol not improve the simulation results, because they only change the level of the peak, but do not induce a second peak. Consequently, extra lengths and velocities will have to be investigated 
to improve the simulation results. Figure 9 further demonstrates that model 1 accurately simulates the heat flux during the compression stroke before and after ignition (part 1 and 2), but that no good agreement is obtained during the expansion stroke.

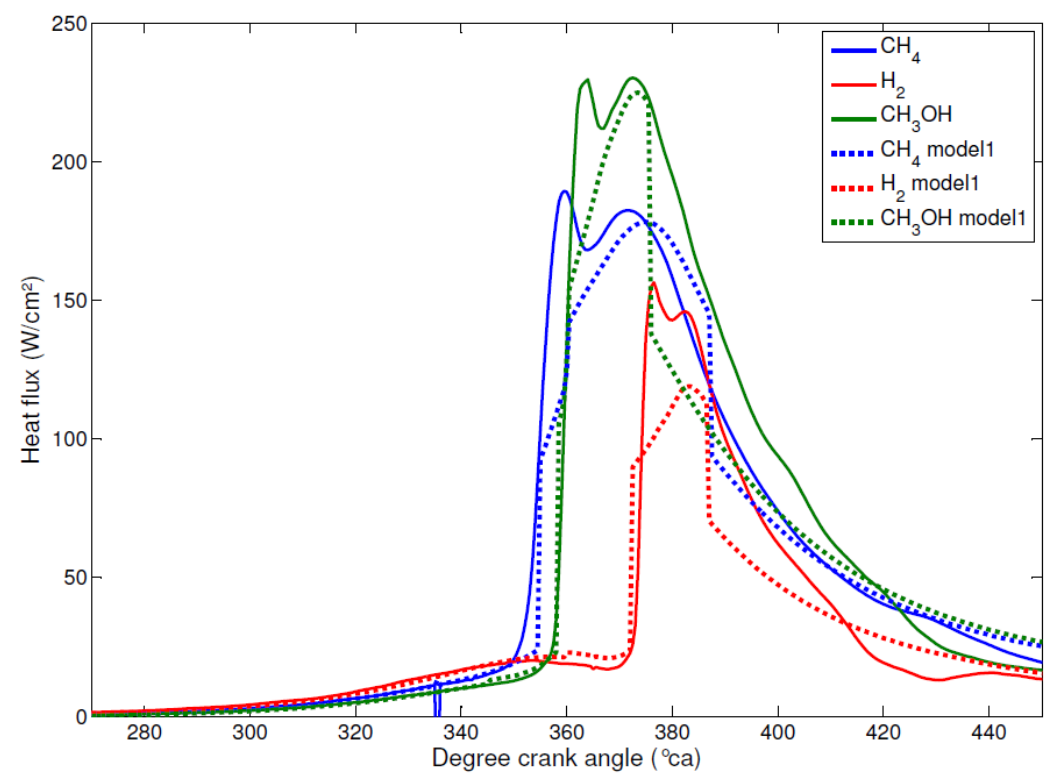

Figure 9: Measured heat flux vs. model predictions for all the factors at level 0 at P2

\section{CONCLUSION}

This paper has presented the validation of a heat transfer model for spark ignition engines, based on the Reynolds analogy, with an experimental database that focuses on the effect of the gas properties. It was shown that the model accurately predicts the heat flux during the compression stroke, both for the measurements under motored and fired operation, if a constant characteristic length and velocity is used. Correct polynomials and mixing laws for the gas properties are indispensible keystone in the accurate results, which is not always the case in models in literature. The simulation results were not accurate in the other parts of the engine cycle. Alternative lengths and velocities proposed in literature also did not result in satisfactory results. Therefore, extra characteristic lengths and velocities will have to be explored, e.g. to better capture the intensified convective heat transfer caused by the propagating flame front.

\section{ACKNOWLEDGEMENTS}

The authors of this paper like to acknowledge the technical assistance of Koen Chielens and Patrick De Pue. The research is carried out in the framework of a Ph.D. which is funded by a grant (SB-81139) of the Institute for the Promotion of Innovation through Science and Technology in Flanders (IWT-Vlaanderen). The experimental equipment is funded by a Research Grant (1.5.147.10N) of the Research Foundation - Flanders (FWO). These financial supports are gratefully acknowledged. 


\section{REFERENCES}

[1] Borman, G.L. and Nishiwaki, K., Internal-Combustion Engine Heat-Transfer. Progress in Energy and Combustion Science, 1987. 13(1): p. 1-46.

[2] Demuynck, J., De Paepe, M., Sierens, R., Vancoillie, J. and Verhelst, S. Literature review on the convective heat transfer measurements in spark ignition engines. in 13th European Automotive Congress (EAEC 2011), paper EAEC2011_A46. 2011. Valencia, Spain. [3] Annand, W.J.D., Heat transfer in the cylinders of reciprocating internal combustion engines. Proc Instn Mech Engrs, 1963. 177(36): p. 973-996.

[4] Morel, T., Rackmil, C.I., Keribar, R. and Jennings, M.J., Model for Heat Transfer and Combustion in Spark Ignited Engines and its Comparison with Experiments. 1988. SAE paper 880198.

[5] Woschni, G., A Universally Applicable Equation for the Instantaneous Heat Transfer Coefficient in the Internal Combustion Engine. 1967. SAE paper 670931.

[6] Welty, J.R., Wicks, C.E., Wilson, R.E. and Rorrer, G.L., Fundamentals of Momentum, Heat and Mass transfer. fourth ed. 2001, New York: John Wiley \& Sons.

[7] Demuynck, J., De Paepe, M., Huisseune, H., Sierens, R., Vancoillie, J. and Verhelst, S., On the applicability of empirical heat transfer models for hydrogen combustion engines. International Journal of Hydrogen Energy, 2011. 36(1): p. 975-984.

[8] Shudo, T. and Suzuki, H., Applicability of heat transfer equations to hydrogen combustion. JSAE Review, 2002. 23(3): p. 303-308.

[9] Kleinschmidt, W., Instationäre Wärmeübertragung in Verbrennungsmotoren: Theorie, Berechnung und Vergleich mit Versuchsergebnissen. Fortschr.-Ber. VDI Reihe 12 nr. 383. 1999, Düsseldorf: VDI Verlag.

[10] Demuynck, J., De Paepe, M., Vancoillie, J., Sileghem, L. and Verhelst, S., Applying Design of Experiments to Determine the Effect of Gas Properties on In-Cylinder Heat Flux in a Motored SI Engine. SAE Int J Engines, 2012. 5(3).

[11] Berger, P.D., Experimental Design with Applications in Management, Engineering, and the Sciences, ISBN: 0-534-35822-5. 2002, Belmont, USA: Duxbury.

[12] GT-Power, Engine Performance Application Manual 2009: Gamma Technologies.

[13] Rowley, R.L., Wilding, W.V., Oscarson, J.L., Yang, Y., Zundel, N.A., Daubert, T.E. and Danner, R.P., DIPPR ${ }^{\circledR}$ Data Compilation of Pure Compound Properties. 2003, New York (NY): Design Institute for Physical Properties, AIChE.

[14] Reid, R.C., Prausnitz, J.M. and Poling, B.E., The properties of Gases and Liquids, 007-100284-7. 1988, Singapore: McGraw-Hill Book Co.

[15] Chang, J., Guralp, O., Filipi, Z. and Assanis, D., New Heat Transfer Correlation for an HCCI Engine Derived from Measurements of Instantaneous Surface Heat Flux. 2004. SAE paper 2004-01-2996. 